\title{
Invasive basosquamous cell carcinoma of the head treated with wide excision and reconstruction with fascia lata graft and two muscle flaps. Case report
}

\author{
Alina Chelmuş ${ }^{1}$, Codrin Nicolae Dobreanu ${ }^{1}$, Atena Florina Tripa ${ }^{1}$, Ramona \\ Filipescu², Angelica Dorina Slătineanu ${ }^{3}$, Daniel Mihai Rusư ${ }^{4}$, Dan Ferariu ${ }^{5}$, Gema \\ Bugean $^{6}$, Cristian Dumitru Lupaşcu ${ }^{7}$, Nicolae Gheţu ${ }^{*, 1,7}$
}

${ }^{1}$ Department of Plastic and Reconstructive Surgery, Regional Institute of Oncology laşi, Romania, ${ }^{2}$ Department of Neurosurgery, "Sf. Maria" Pediatric Emergency Hospital laşi, Romania, ${ }^{3}$ Department of Radiology, Regional Institute of Oncology laşi, Romania, ${ }^{4}$ Department of Anesthesia and Intensive Care, Regional Institute of Oncology laşi, Romania, ${ }^{5}$ Department of Pathology, Regional Institute of Oncology laşi, Romania, ${ }^{6}$ Department of Radiotherapy, Regional Institute of Oncology laşi, Romania,

7 "Grigore T. Popa" University of Medicine and Pharmacy, Iaşi, Romania

\begin{abstract}
Background: Basosquamous carcinoma (BSC) is a variant of basal cell carcinoma subtype that is locally aggressive with high tendency for recurrence and metastasis and a poor prognosis. Up to $95 \%$ are located in head and neck area. Treatment for invasive BSC with aggressive growth pattern is wide excision and reconstruction. Complex defects require free tissue transfer to protect underlying structures and to sustain the adjuvant radiotherapy.

Case report: A 57 year-old male presented with ulcerated, bleeding tumors in frontal and periauricular area, identified as BSC on biopsy. CT-scan revealed contact to dura mater. Wide excision included frontal bone and dura mater, frontal sinus, lateral orbital wall and exenteration, ear en-bloc with parotid gland. Dura mater was replaced with fascia lata graft, frontal sinus was filled with pedicled temporalis muscle and $20 / 25 \mathrm{~cm}$ soft tissue defect was covered with free Latissimus dorsi muscle anastomosed to superior thyroid artery and internal jugular vein branch, respectively. The muscle was skin grafted 14 days later.

Results: Postoperative recovery was complicated: cerebrospinal fluid leak, extradural hematoma, posthemorrhagic anemia, pneumonia, and withdrawal syndrome, remitted under specific treatment. Muscle flap survived entirely with skin graft fully integrated. Positive margins on dura mater and mastoid bone required radiotherapy.

Conclusions: Wide excision of head invasive BSC resulted in complex defect reconstructed with fascia lata graft, temporalis muscle and Latissimus dorsi free flap grafted secondarily. Short-term evaluation showed no recurrence and good life-quality; follow-up is needed to evaluate long-term results. Interdisciplinary approach is the key for patient's successful treatment.
\end{abstract}

Keywords: basosquamous carcinoma, head and neck, wide excision, Latissimus dorsi free flap, interdisciplinary approach

Received: May 2015; Accepted after review: June 2015; Published: June 2015.

${ }^{*}$ Corresponding author: Nicolae Gheţu, Department of Plastic and Reconstructive Surgery, Regional Institute of Oncology laşi, "Grigore T. Popa" University of Medicine and Pharmacy, 2-4, Gen. Henri Mathias Berthelot St., 700483 laşi, Romania

Email: dr.ghetu@gmail.com

\section{Introduction}

Basosquamous carcinoma (BSC) was first described by Hamilton in 1928 as an aggressive basal cell carcinoma subtype [1]. It is frequently underdiagnosed, due to 
macroscopic resemblance with the basal cell carcinoma [2, 3].

Up to $95 \%$ of BSC are located in the head and neck area and have a poor prognosis as a result of high tendency for recurrence and metastases [2, 4].

The treatment is wide excision with complete peripheral and deep margins assessment and long-term follow-up, both clinical and CT scan [5-7].

Invasive BSC with bone and meningeal involvement yields complex defects, challenging to reconstruct. For defects larger than $50 \mathrm{~cm}^{2}$, free flap reconstruction is advised [8]. Exposed brain requires dura mater plasty and soft tissue coverage to protect the underlying structures and to sustain the adjuvant radiotherapy.
Due to poor long term results, primary radiotherapy is advised for inoperable tumors on lower eyelid, lips, nose, and ear, elders, patients without connective tissue diseases [57].

Adjuvant radiotherapy is critical for patients with high risk of recurrence - positive margins, perineural involvement, bone invasion and aggressive histologic features [9].

\section{Case presentation}

A 57 year-old male presented ulcerated tumor in the right frontal area fixed to the bone, with retracted eyebrow and eyelids.

The patient presented a second tumor fixing the ear to the parotid gland (Figure 1).
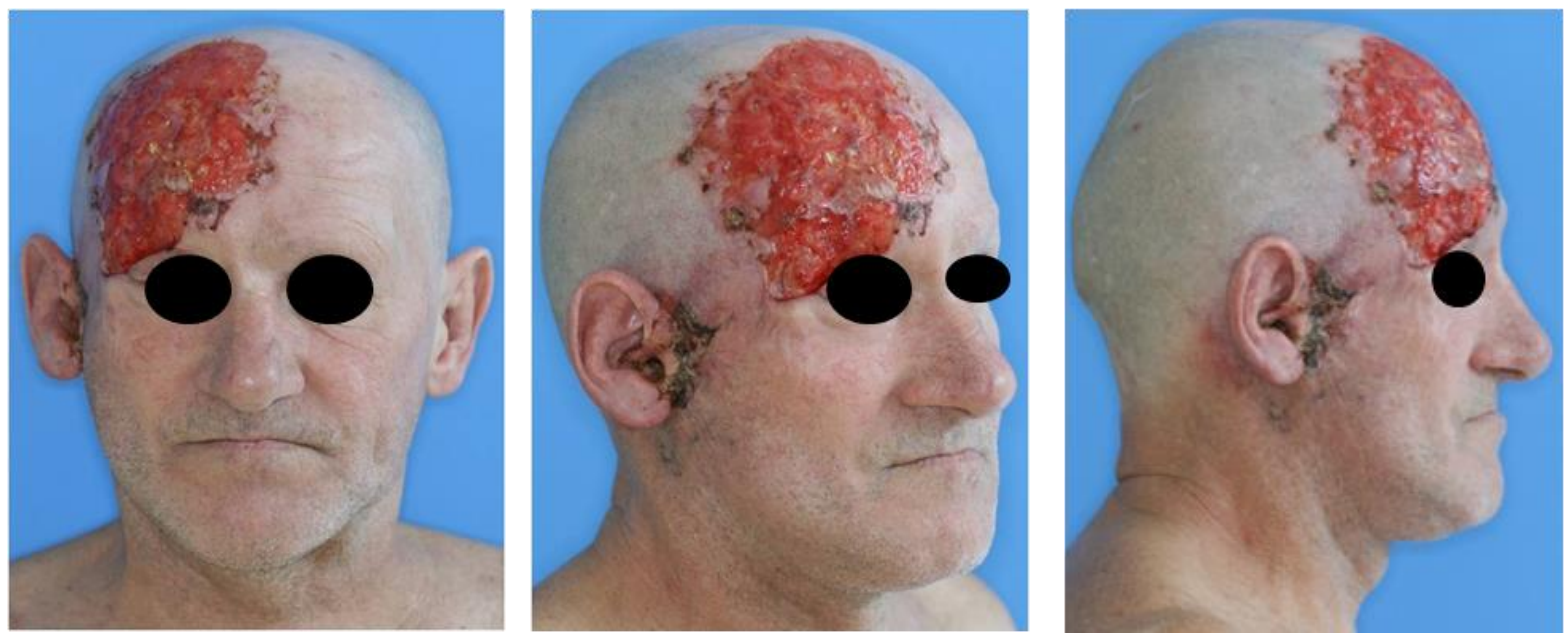

Fig. 1. Frontal and preauricular tumors: Left - frontal aspect. Middle - right oblique anterior view. Right - view.

CT-scan showed tumor extension to dura mater, superior and external orbital walls, superior rectus muscle (Figures 2-4) and frontal sinus and involvement of the right superficial parotid lobe and the external ear canal. Preoperative biopsy indicated BSC.

The patient had no significant medical history.

The Oncologic Board decided wide excision of tumor and invaded tissues with safe margins, followed by reconstruction; follow-up plan and adjuvant treatment took final histology into account.

The patient agreed to the proposed treatment after explanations from both plastic surgeon and neurosurgeon were provided.

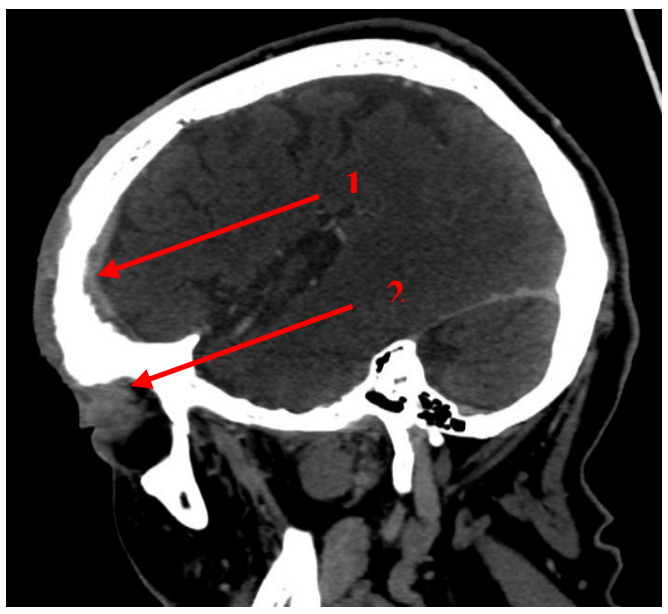

Fig. 2. Preoperatory CT-scan sagittal view: tumor extension in contact to dura mater (arrow 1), superior rectus muscle and eyeball (arrow 2). 


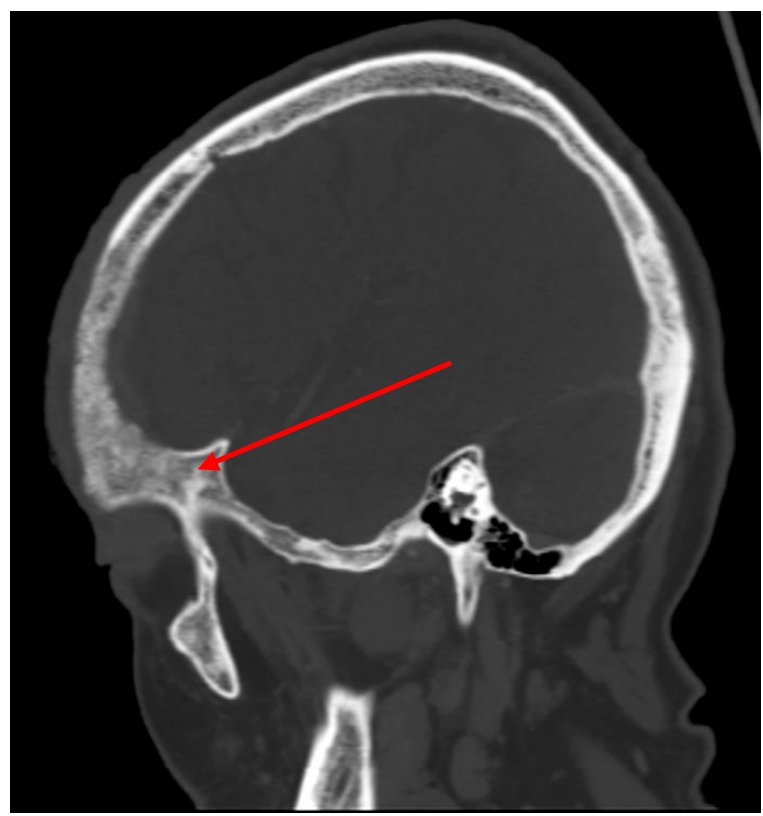

Fig. 3. Preoperatory CT-scan sagittal view: the tumor invading the frontal bone, in vicinity of the frontalzygomatic suture (arrow 3)

Anesthesiologist had their informed
consent taken. Skin was incised
circumferentially at $2 \mathrm{~cm}$ from tumor
macroscopic margins, down to the bone. Wide
right fronto-orbital craniectomy en-bloc with

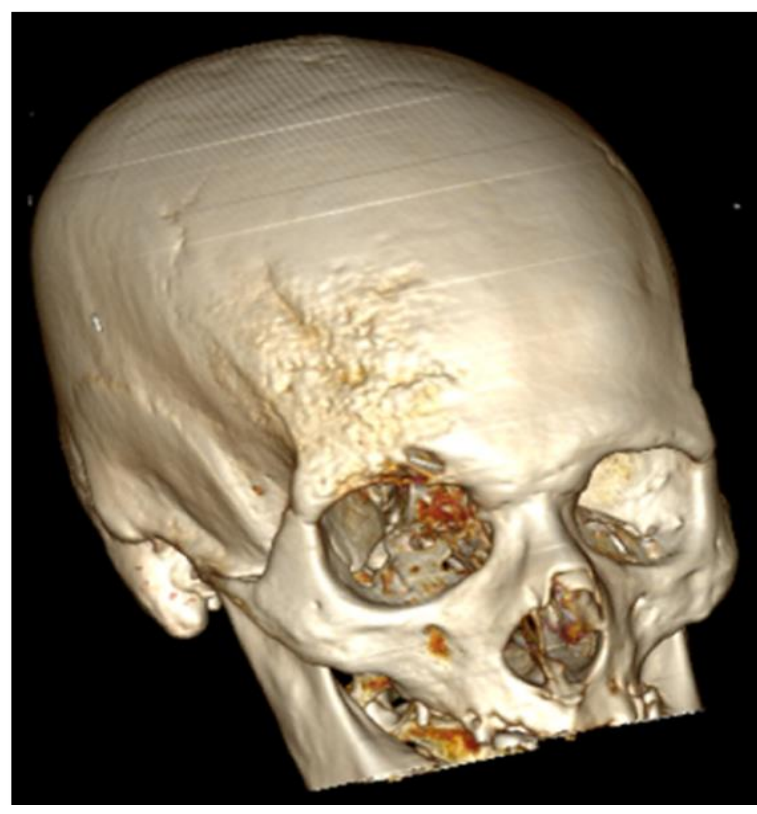

Fig. 4. CT-scan with 3D reconstruction of the skull: outer cortex of the right frontal bone, superior and lateral orbital walls affected.

right frontal sinus, lateral orbital wall and zygomatic bone partially was performed, also at $2 \mathrm{~cm}$ from tumor margins on CT-scan (Figure 5).
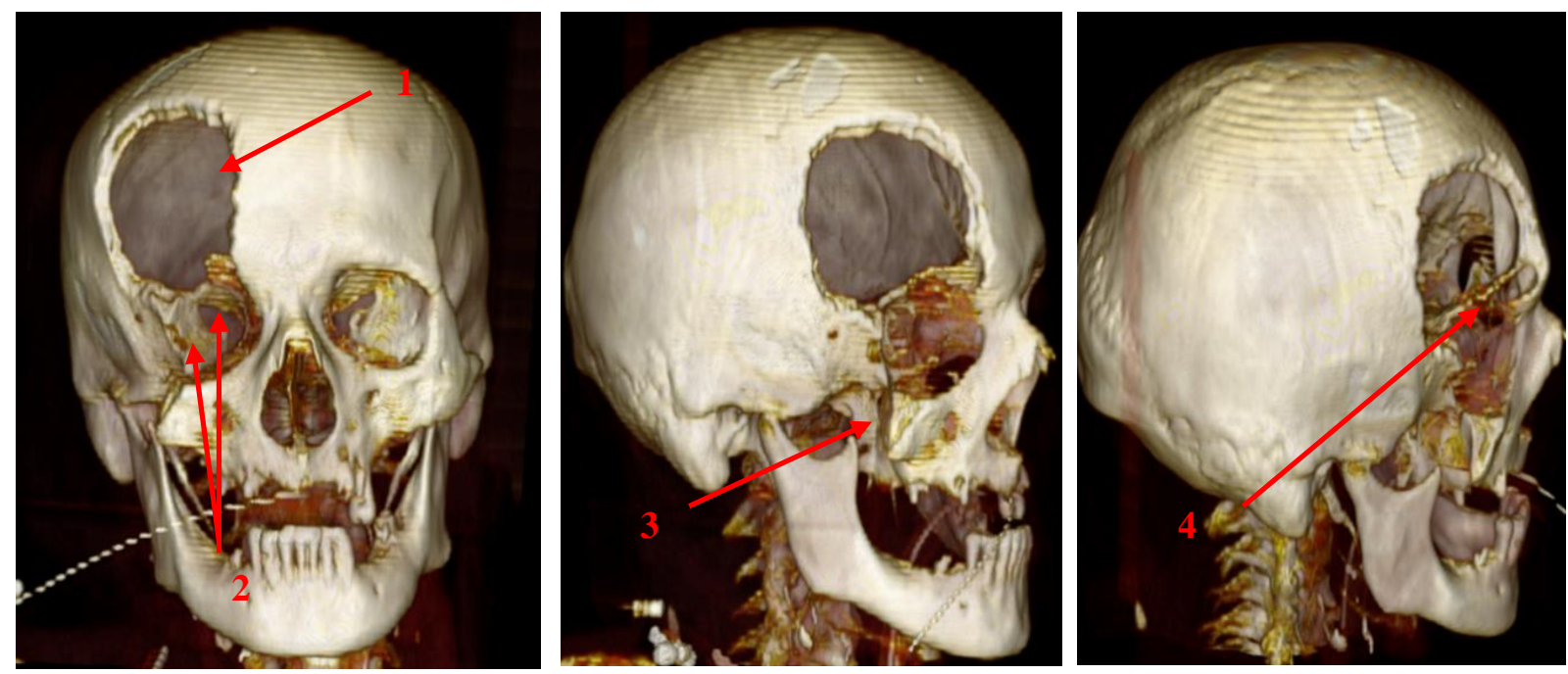

Fig. 5. CT scan with 3D reconstruction of the skull: Left - the defect after excision of the right frontal bone (arrow 1), superior and lateral orbital walls, respectively (arrows 2); Middle - partial zygoma excision (arrow 3); Right right frontal sinus defect (arrow 4). 
Invasion of orbital content - superior rectus muscle and the eyeball required orbital exenteration. Dura mater was excised in circular fashion with wide margins. Epidural thin layer collection resembling tumor and puss was followed laterally until normal macroscopic dura mater appearance. The adherence between inner aspect of dura and external ear canal were excised. The subperiosteal excision of the external ear canal went down to the tympanic membrane. Excision of soft tissue was guided by serial superficial cerebral vessels made the dissection tedious. Dural margins were suspended with silk sutures to prevent postoperative epidural hematoma.

At $2 \mathrm{~cm}$ from second tumor margins the skin incision went circumferentially around the ear. The pavilion en-bloc with invaded parotid gland, facial nerve, masseter muscle and frozen sections and the bone was removed by macroscopic appearance and clinical judgement taking into account the local conditions.

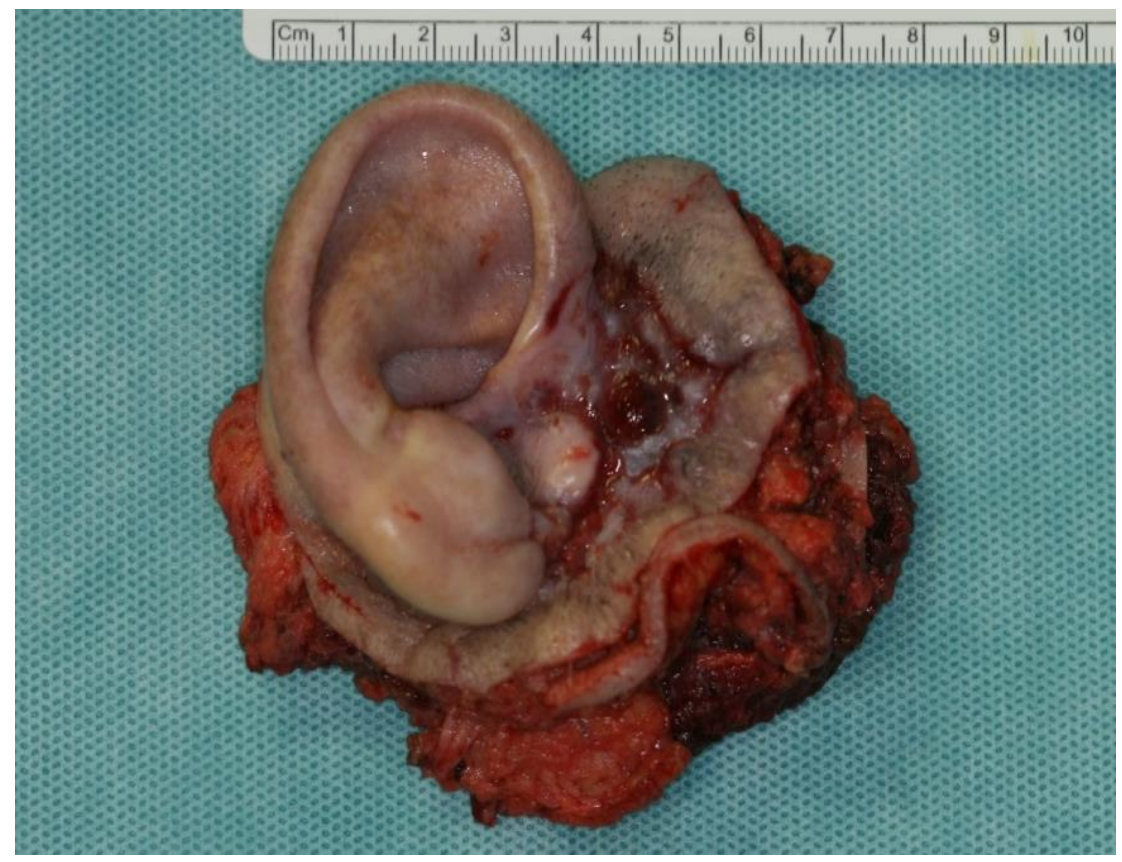

Fig. 6. Ear en-bloc with parotid gland, facial nerve and masseter muscle were excised with $2 \mathrm{~cm}$ safety margins from tumor edges

The temporalis muscle was raised in pedicled fashion, rotated and fixed to fill the right orbit and frontal sinus. Dura mater defect of $9 / 8 \mathrm{~cm}$ with exposed brain was reconstructed with fascia lata (FL) from ipsilateral thigh, sutured in watertight fashion in order to prevent postoperative cerebrospinal fluid (CFS) leak continuous locking manner to prevent postoperative CSF leak (Figure 7).

With the patient on left lateral decubitus, right Latissimus dorsi muscle flap was harvested on thoracodorsal pedicle.

Donor area was closed using our preferred method - quilting sutures, double layers for incision on 2 suctions drains. The muscle was transferred to cover the $20 / 25 \mathrm{~cm}$ post- excisional defect. Under microscope magnification, thoracodorsal pedicle was anastomosed to superior thyroid artery and a branch of internal jugular vein, respectively. Muscle flap was covered with Vaseline gauze and donor sites were closed in standard fashion.

Flap was monitored by visual exams and pin-prick every 2 hours for 3 days and every 6 hours thereafter.

The patient underwent monitoring for microsurgical cases according to ICU protocols.

Postoperative day (POD) 14 the muscle flap was grafted using split thickness skin harvested from anterolateral left thigh. 

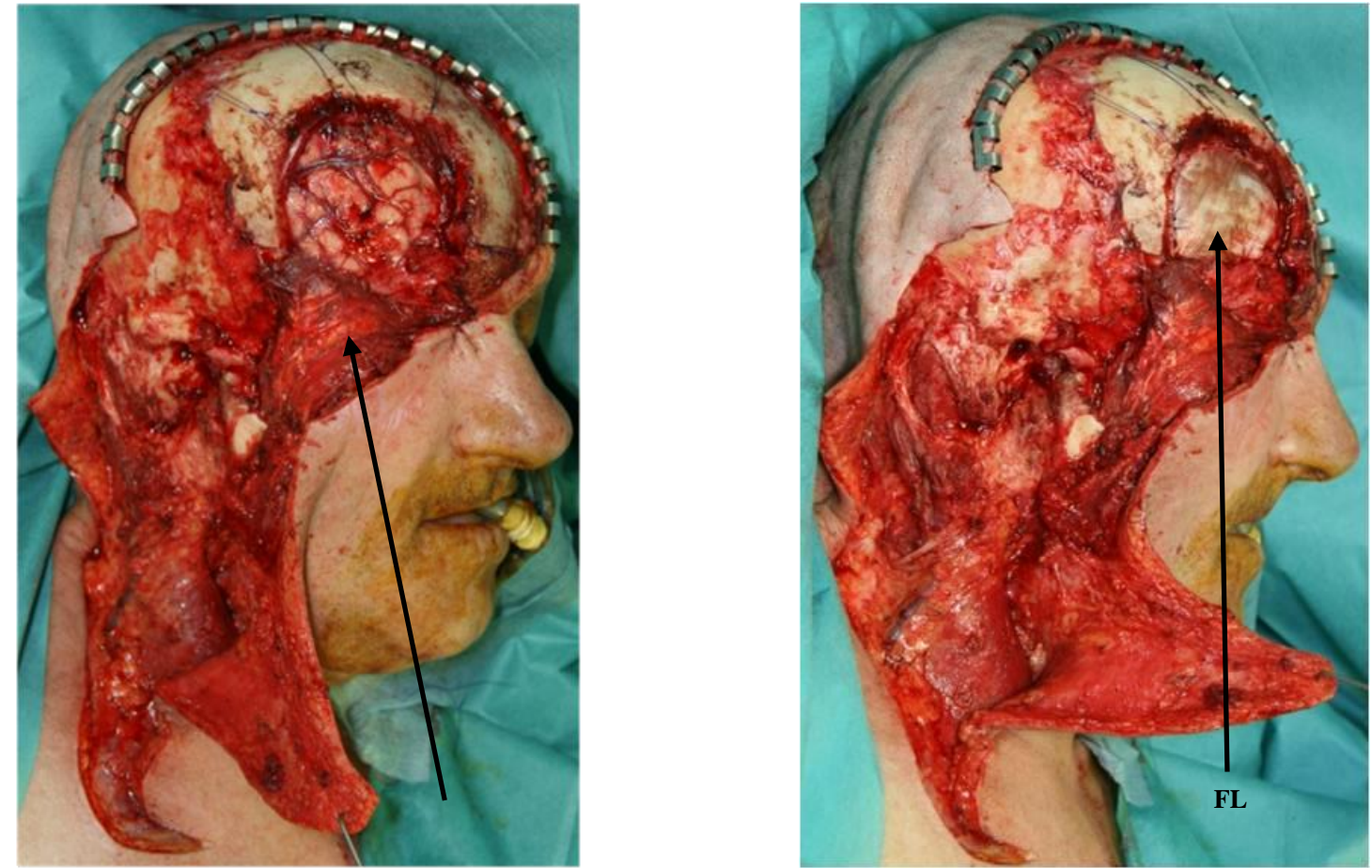

Fig. 7. The defect resulted after wide excision. Left - pedicled temporalis muscle was fixed in the right orbit and frontal sinus caudal from exposed brain. Right - dura mater was reconstructed using FL graft sutured circumferentially to the defect edges

\section{Results}

The operation lasted for 17 hours and 2 combined teams including neurosurgeon rotated on the operating sites. Exposed brain was covered with FL graft; the orbit and frontal sinus were filled with pedicled temporalis muscle. Defect of 20/25 cm was covered with LDFF; the muscle was normally perfused throughout the postoperative period, completely covering the defect, with no signs of necrosis or hemorrhage (Figure 8).
Drainage in LD donor area was removed on POD 8; donor sites (trunk and thigh) healed uneventfully. Split-thickness skin graft was fully integrated at discharge POD 23.

On POD 2 after extubation, CSF started leaking through right frontal sinus and nose and posterior margin of the inset flap. External lumbar drainage released the intracranial fluid pressure and allowed for FL sealing by POD 20 when the device was removed. Daily drainage dropped from $125 \mathrm{cc}$ to $10 \mathrm{cc}$, to a total amount of $765 \mathrm{cc}$.
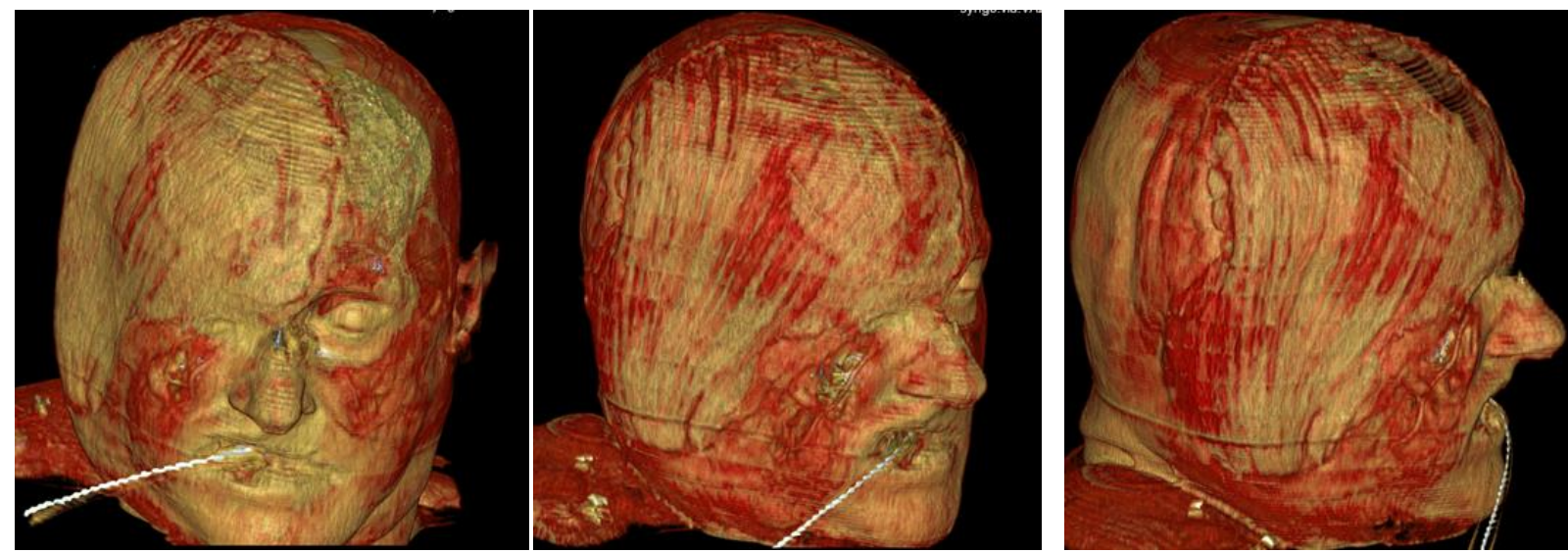

Fig. 8. 3D reconstruction at POD 5 shows LDFF providing complete coverage. Left - frontal aspect. Middle - right oblique anterior view. Right - lateral aspect. 
On day 4 of ICU stay the patient developed anxiety, fever, coughing, rapidly progressing to respiratory hypoxemic failure that imposed sedation, intubation and mechanical ventilation. Bilateral nosocomial pneumonia was treated with antibiotics and respiratory gymnastics. Despite recovery from respiratory failure and pneumonia, 7 days after ventilation the patient experienced problems in withdrawal from ventilator with two failed extubation attempts. Daily spontaneous breathing trials with proper adjustment of CSF pressure induced by changes in respiratory mechanics decided the right point of patient's withdrawal from respirator. After 12 days of ventilation the patient was extubated with no further respiratory complications.

A small left frontal epidural hematoma showed on CT scan; it was asymptomatic and resolved in time. Postoperative neurological examination was normal. 3D reconstruction showed no signs of intracranial hypertension or cerebral herniation.

The final histology exam confirmed BSC with perineural involvement, positive margins on dura mater and mastoid bone and one positive lymph node, undecided between local invasions vs. lymphatic metastasis (Figure 9). The deep biopsies from under the dura mater were all negative.

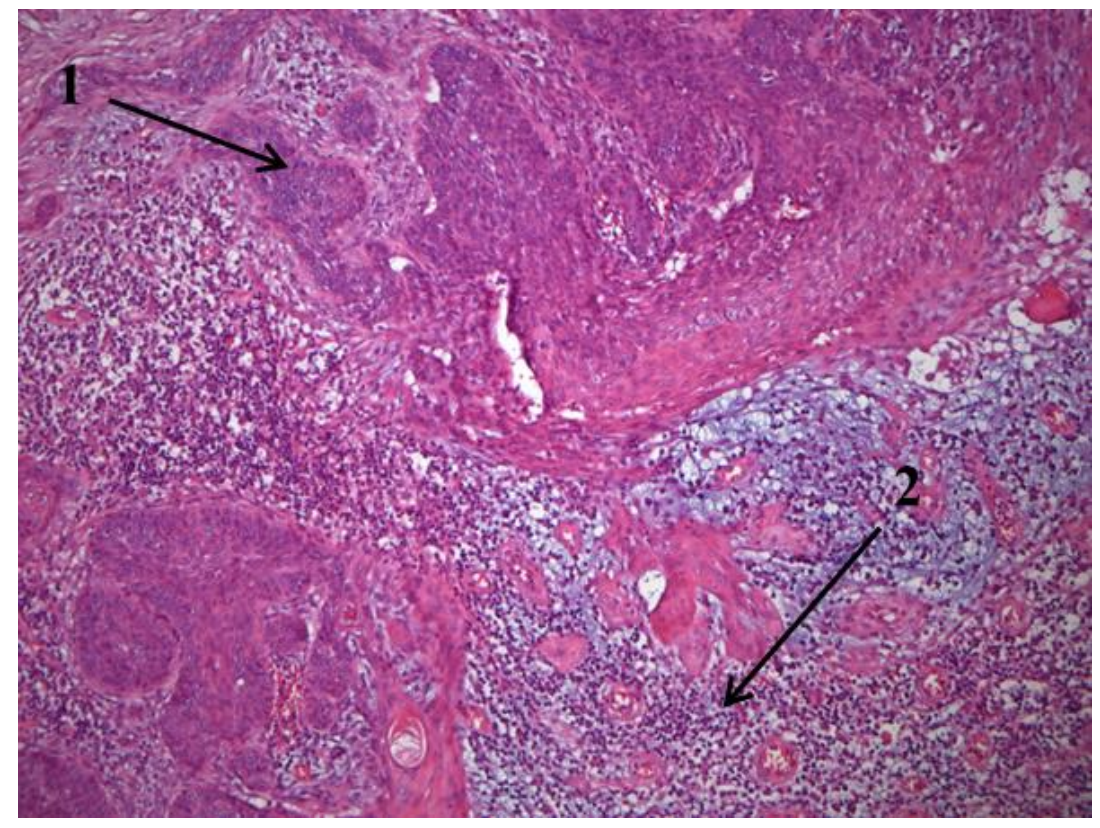

Fig. 9. Final histology exam: representative aspect for BSC - nests of basaloid cells with peripheral palisading (arrow 1) in contact with zones of typical squamous proliferation (arrow 2).

Oncologic Board recommended radiotherapy using an association between electrons and photons beams due to different depths of irradiated volume. The target includes tumor bed based on preoperative assessment and histology features, with margins for microscopic spread up to $20 \mathrm{~mm}$. The radiotherapy of 70 Gy was fractioned by 2 Gy daily, 5 days per week for totally 7 weeks, with the patient immobilized in a thermoplastic shell to achieve stability and to maximize setup reproducibility. Follow-up included complete clinical examination monthly in the first year and CT-scans every 6 months for the first 3 years. Assessment for radiation related toxicity focused on weight loss, fatigue, xerostomia and oral mucositis, dysphagia, local erythema and desquamation.

Four months after surgery and undergoing radiotherapy, there were no local signs of recurrence. Peripheral facial nerve palsy in middle and lower thirds of the right hemiface did not impact patient's life quality; he did not complain about limited visual field as his left eye compensates for basic daily life (Figure 10).

No quantitative evaluation or questionnaires were applied. 

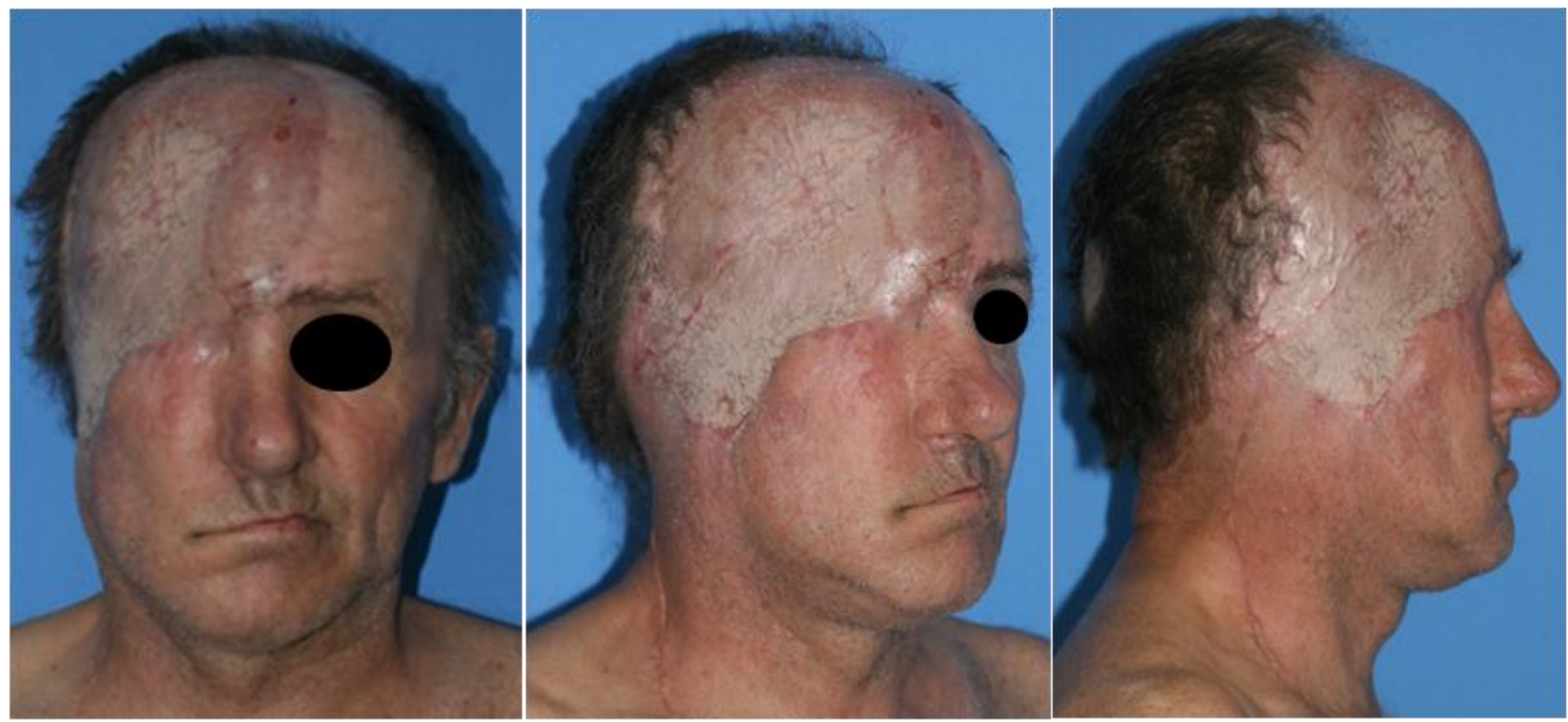

Fig. 10. Outcome at 4 months $\mathrm{PO}$ - viable flap and skin graft integrated, with no signs of local recurrence. Muscle flap shrinkage due to atrophy yields a nice contouring with the neighboring tissues. Zygoma stump allows for symmetric central area of the face middle third. Left - frontal aspect. Middle - right oblique anterior view. Right

- lateral view.

\section{Discussion}

A 57-year-old male with BSC in the right frontal and periauricular area, extended to dura mater, orbit, parotid gland and the external ear canal, underwent wide excision and primary reconstruction using FL graft for dura mater and two muscle flaps - pedicled temporalis and LDFF. Positive margins on dura mater and the mastoid bone required adjuvant radiotherapy.

BSC is a rare subtype of basal cell carcinoma with high proliferative activity, locally aggressive and distance metastasis potential $[2,3,10]$. Developing mainly in the head and neck area, BSC is clinically undistinguishable from other basal cell carcinoma types [2, 4]. Histological exam before treatment planning is critical for recurrence prognosis and long term results [3, $5,10]$.

The primary treatment is wide excision of the tumor with oncologic margins in order to prevent local recurrence. For high risk patients increased surveillance with prophylactic measures are needed, in order to reduce the recurrence rate [5].

Nonsurgical treatment options are limited, with unsatisfactory long-term results [11, 12]. Primary radiotherapy applies when surgery is contraindicated, elders, small tumors with a non-aggressive pattern and has a reported recurrence rate of $7.5 \%$, compared to $0.7 \%$ for surgical excision. Radiotherapy alone is unable to provide margin assessment [5-7, 13]. However, the main indication is as adjuvant treatment for positive margins or perineural involvement $[5,13]$. The local control after excision of different types of basal cell carcinoma with perineural involvement and adjuvant radiotherapy is $97 \%$ [9].

Surgical excision is considered the gold standard treatment for any type of basal cell carcinoma, including BSC. The excision is guided by frozen sections or Mohs micrographic technique [5].

The main advantages of Mohs surgery are the accuracy of margin assessment and the possibility of soft tissue preservation $[12,14]$. In addition, Leibovitch et al, in a prospective study highlighted the lower recurrence rate for BSC treated with Mohs technique [4]. In a prospective randomized controlled trial, van Loo et al estimate the cumulative probability of recurrence rate $4.4 \%$ for Mohs surgery vs. $12.2 \%$ for standard excision [12]. However, in a randomized trial, comparing Mohs technique with classic excision, there were no statistical differences between the two, regarding basal cell carcinoma recurrence $[6,15,16]$. 
Row et al recommend Mohs surgery for recurrent basal cell carcinoma treatment [16, 17]. Exceeding the advantages, it is timeconsuming and costs are greatly higher than classic excision [6].

Furthermore, Mohs surgery is used for cutaneous lesions, without bone involvement [14]. We chose the frozen section samplings due to its straightforward and the advantage to help timely-fashion excision. Skin tumors with bone and deeper invasion cannot be excised and brain let open until final pathology report is released few days later. Clinical and preoperative imageries assessment oriented the gross excision margins and for deeper and circumferential areas we do follow "sample as you go".

However, frozen sections extensive tissue sampling from wide postexcisional defects carries the risk that positive margin may be overlooked. From a 20/25 cm excision area, only two samples turned to be positive, one in dura mater and second in mastoid bone, showing frozen sections limitations.

Our patient was included in a high risk category for recurrence based on histological type, scalp and forehead location, size over 10 $\mathrm{mm}$ with poorly defined borders, aggressive growth pattern and perineural involvement, requiring wide excision, reconstruction with adjuvant radiotherapy [5].

The 57 year-old patient, without morbidities or contraindications for surgery, was suitable to undergo excision and reconstruction. Due to wide excision of soft tissue, calvarial bone and dura mater, immediate reconstruction was necessary in order to protect the brain tissue. Dura mater substitutes vary from autografts to semi/synthetic and xenografts.

Autografts are preferred, due to texture close to human dura, flexibility, good tensile strength, non-immunogenic and disease-free. Fat grafting is not suitable for sizable defect of dura mater with exposed brain, and also the temporalis fascia or the pericranium was insufficient to achieve coverage $[18,19]$.

FL was harvested by the second team while neurosurgeon completed the excision. Concomitant operations were decided in order to expedite the surgery and the thigh donor scaring site was considered acceptable [18].
Moreover, the surrounding scalp and pericranium was left intact as a reliable lifeboat in case of minor flap loss or secondary revisions without the need for complex reconstruction or another donor site.

Scalp reconstruction is challenging after wide excision, not because of the amount of tissue lacking but because of complex defect. Even though highly vascularized, the scalp has decreased elasticity, which leaves few reconstruction techniques available for large defects [8]. Small frontal defects can be covered with rotated flaps; however there are few techniques using local flaps to grant total coverage.

Orticochea flap is not a choice for our patient due to scarce remaining soft tissue. In combined frontal and face defects, the remaining scalp is largely insufficient as donor. Rule of thumb, for a defect over $50 \mathrm{~cm}^{2}$, is recommended coverage using local or free flap $[8,20,21]$. For herein patient the soft tissue defect was 20 per $25 \mathrm{~cm}$. Moreover, dura mater repair using non-vascularized autograft needed well vascularized tissue for coverage, also in view of subsequent radiotherapy.

Several free flaps are available for large defects in head and neck area, either cutaneous, muscular or combinations. ALT is preferred for scalp reconstruction, for medium size defects [22-26]. The main disadvantage of the ALT flap is unpredictable vascular anatomy, which can increase the surgery time $[27,28]$. The perforator arteries require meticulous dissection and are less resistant to compression, contamination or infection [28]. When ALT is raised with a large muscle component the risk of developing complications is higher [28]. If is harvested with a large skin surface, the donor site is not able to be closed primarily, requiring a skin graft which is also associated with a higher rate of complications and decreased ambulation for first 2 weeks postoperatively. The more complex the ALT with inclusion of adjacent tissues on the same pedicle, the more increased the chance to develop complications.

Multiple flaps 3D arrangements to achieve recipient site requirements are very difficult if the anatomy is not favorable $[29,30]$. For our 
patient the ALT size was insufficient, unable to ensure complete coverage.

For subtotal or total scalp defects the only free flaps large enough to ensure complete coverage are the omentum flap and the LDFF [31]. The omentum free flap with splitthickness skin graft for scalp defects, first described by McLean and Bunck in 1972, needs laparotomy with increased morbidity at the donor site. Although easy to fold on a flat surface, on the head the omental flap suspension is tedious. Moreover, postoperative ambulation is limited until flap will adhere to the recipient site [22-24].

Latissimus dorsi has a reliable anatomy and is easy to harvest with minimal acceptable donor site morbidity and atrophy of the muscle provides a soft tissue thickness that closely approximates that of the native scalp $[23,25$, 31]. LD offers more tissue bulk (thickness range $0.5-4.5 \mathrm{~cm}$ with an average of $1.5 \mathrm{~cm}$ ) and secondary surgery such as calvarial reconstruction is possible [25, 31].

Fattah et al in case series report on giant head and neck basal cell carcinoma with bone and dura mater involvement, in two out of three cases chose LD for soft tissue defect coverage [32]. Hiernet et al favors the LDFF over the omental flap [31]. Skin grafting was postponed due to long operating time; it is our preference for delayed skin grafting. There was no donor-site morbidity in our case and entire muscle survived on single pedicle.

The paranasal sinuses need to be covered in order to protect the brain against nasal contamination [33]. Whenever dura resection and reconstruction are associated with orbital exenteration, primary coverage of the orbit is critical for protection against meningitis [34].

Due to complex defect, it is difficult for single muscle flap to achieve orbital, sinus and large defect coverage on top of it. Even though trimming and folding of the large surface muscle like LD could have provided all requirements, possible failure of the free flap would have left the whole recipient area open again.

Our strategy is damage-control oriented: one flap for orbit and sinus coverage and a second flap for large defect coverage. Even if the free flap on top of first flap fails, the barrier from nose area can still prevent contamination while preparing the second free flap operation. Temporalis muscle was reported as a very good choice for barrier to intracranial communication [35]. For our patient, the temporalis muscle was raised in pedicled fashion, rotated and fixed to fill the remaining of the right orbit and frontal sinus in a timelyfashion manner. The technique is straightforward, the muscle is readily available and the contouring is satisfactorily achieved using the muscle bulk. With smooth surfacing, due to zygoma excision and temporalis muscle coverage, LD mission to resurface the defect was achieved easily with improved final contouring.

Another option for orbital and sinus coverage is the chimeric flap of serratus anterior and LD [36]. The main drawback is the functional disabilities from sacrificing two muscles [37]. The serratus anterior muscle enables full abduction and flexion of the arm and sacrificing it will lead to "winging" of the scapula. The patient will be unable to elevate an arm above the horizontal plane [38]. Herein, the temporalis muscle was chosen due to defect proximity, minimal donor site comorbidities and shorter operating time.

Composite scalp and calvarial defects can undergo primary simultaneous reconstruction or scalp only reconstruction, knowing that there is no significant difference in complication rate between the two methods [39]. However, primary calvarial and zygoma reconstruction is contraindicated when the paranasal sinuses are opened; moreover, alloplastic material exposure rate after radiotherapy is increased [40]. Due to high recurrence risk, adjuvant radiotherapy and close follow-up required, the patient underwent scalp reconstruction without bone replacement. Later reconstruction of the upper third of the right face will be granted after 3 years follow-up with no recurrence. From our point of view, the nice contouring of the face middle third doesn't require zygoma reconstruction. Eye reconstruction with prosthetics and lid reconstruction is also feasible, after oncologic follow-up.

PO complications after major head and neck surgery (involving free flaps) include medical complications and those related to donor and recipient site [41-43]. Most frequent 
major complications are respiratory failure and pneumonia. In a prospective cohort study on 192 patients who underwent major head and neck surgery with free flap repair, 49 developed pneumonia [43]. Perisanidis et al reviewed 79 patient who underwent major head and neck surgery: $43 \%$ had pulmonary complications, from which $9 \%$ with respiratory failure [41]. McMahon et al report 8 cases of delirium out of 192 patients [42]. A frequent minor complication reported in the literature is the need for transfusion, as Perisanidis et al reported in $39 \%$ cases [43]. In a retrospective study on 282 patients who underwent head and neck surgery with free flap reconstructions, there was no statistical difference in flap failure rate between patient with transfusion vs. no transfusion group.[44]

The risk factors related with $\mathrm{PO}$ complications are the area of surgery, neck dissection, operating time, comorbidities and alcohol consumption [41, 42]. Herein, the patient developed PO pneumonia, posthemorrhagic anemia, and withdrawal syndrome, remitted under specific treatment.

For CSF leak through frontal sinus the patient underwent external lumbar drainage for 12 days and antibiotics. The CSF leak is very difficult to be avoided after craniectomy with dura mater plasty. In a prospective multicenter analysis study, the frequency of CSF leak is $7.7 \%$ [45]. Most of them respond to external lumbar drainage from 48 hours up to 10 days and only $2 \%$ require surgery. After the CSF leak subsides, is recommended to keep the drainage another 3 to 5 days in order to provide time for the fistula to heal [46]. Craniotomy, CSF leak and the effusion found in the frontal sinus during surgery are risk factors for meningitis [45, 47].

POD 9 CT scan reevaluation revealed an extradural hematoma, which slowly resolved without motor impairment under conservatory treatment. In literature, the cases in which this complication occurs after head surgery ranges from $0.8 \%$ up to $1.3 \%$ [48]. Pichierri et al recommend conservatory treatment for small extradural hematoma, if the neurological status of the patient permits [48].

Final histology showed positive margins on dura mater and the mastoid bone. Sherry et al in a retrospective study reported $3.2 \%$ rate of positive margins after standard excision for different histologic types of basal cell carcinoma, including BSC [49]. There are no clear protocols in managing incomplete excision. In literature, three types of approaches are described when positive margins are involved: re-excision, adjuvant radiotherapy and wait-and-see.

A retrospective study reveals $25 \%$ cases of recurrence out of $62 \%$ patients with positive margins who underwent observations [49]. Liu et $\mathrm{al}$, in a study in which 120 patients underwent radiotherapy and 67 were under observations after surgical treatment, reported $6 \%$ recurrence rate for adjuvant radiotherapy and $31 \%$ for the patients under observation $[50,51]$. For our patient the decision was for adjuvant radiotherapy, due to BSC aggressive features and high risk of recurrence and positive margins. Close follow-up with complete clinical examination monthly in the first year and CT-scans at every 6 months for the first 2 years are advised [5].

Facial nerve palsy morbidity is major for the eye with less morbidity for middle and lower face [52]. The patient did not complain of motor function absence on right hemiface.

Perisanidis et al report a median duration of hospitalization stay after free flap surgery of 34 days (22-48 days) when major complications are involved [41]. One of the most important factors for hospital stay in head and neck surgery is operation time. Lofti et al report a hazard ratio of 1.34 for surgeries longer than 220 minutes vs. those lasting under 220 minutes [53]. A cost-effectiveness analysis of 39 free tissue transfers reported an average cost of $24.737 €$ per case with 16 days of hospitalization [54]. Our patient was discharged after major head and neck surgery that lasted 1020 minutes and 23 days of PO recovery, with viable flap and split-thickness skin graft fully integrated, overall cost of hospitalization and treatment was $5000 €$.

\section{Conclusion}

Patient with invasive BSC can benefit from major surgery comprising wide excision and soft tissue extensive reconstruction. Interdisciplinary approach with assessment 
from pathology and radiology specialists helps designing the operating plan. Intense reanimation, follow-up and radiotherapy for positive margins are mandatory. This holistic approach yields no recurrence on short-term evaluation.

Further follow-up and life-quality assessment is needed. The cost-benefit ratio is favorable.

\section{References}

1. Hamilton M. Basal squamous cell epithelioma. Arch Derm Syphilol 1928; 18(1):50-73.

2. De Stefano A, Dispenza F, Petrucci AG, et al. Features of biopsy in diagnosis of metatypical basal cell carcinoma (Basosquamous Carcinoma) of head and neck. Otolaryngol Pol 2012; 66(6):419-423.

3. Garcia C, Poletti E, Crowson N. Basosquamous carcinoma. J An Acad Dermatol 2009; 60(1):137-143.

4. Leibovitch I, Huilgol SC, Selva D, et al. Basosquamous carcinoma: treatment with Mohs micrographic surgery. Cancer 2005; 104(1):170-175.

5. Clinical Practice in Oncology - Basal Cell Skin Cancer. NCCN 2015. [http://www.nccn.org/professionals/physician gl $\mathrm{s} / \mathrm{f}$ guidelines.asp available at 06.15.2015]

6. Smith V, Walton S. Treatment of Facial Basal Cell Carcinoma: A Review. J Skin Cancer 2011; doi:10.1155/2011/380371.

7. Rigel DR, June K, Robinson JK, et al. Cancer of the Skin. $2^{\text {nd }}$ Ed. China: Elsevier Saunders; 2011. Chapter 52, Radiation therapy in the treatment of skin cancers; p. 578-581.

8. Newman Ml, Hanasono MM, Disaj JJ, et al. Scalp Reconstruction: A 15-Year Experience. Ann Plast Surg 2004; 52(5):501-506.

9. Plichta K, Mackley HB, Radiotherapy for cutaneous malignancies of the head and neck. Operative Techniques in Otolaryngology 2013; 24(1):59-62. doi:10.1016/j.otot.2012.12.004.

10. Hussain SI, Hussainy AS. Baso-Squamous Cell Carcinoma - a Case Report. Pak Med Assoc 2004; 54(1):30-32.

11. Cognetta $A B$, Howard $B M$, Heaton $H P$, et al. Superficial $x$-ray in the treatment of basal and squamous cell carcinomas: A viable option in select patients. J Am Acad Dermatol 2012; 67(6):1235-1244.

12. van Loo $E$, Mosterd $K$, Krekels GAM, et al. Surgical excision versus Mohs' micrographic surgery for basal cell carcinoma of the face: A

\section{Disclosure}

The authors have no conflict of interests to declare.

\section{Acknowledgement}

This paper was published under the frame of European Social Found, Human Resources Development Operational Program 2007-2013, project no. POSDRU/159/1.5/S/136893.

randomised clinical trial with 10 year follow-up. Eur J Cancer 2014; 50(17):3011-3020.

13. Aguayo-Leiva IR, Ríos-Buceta $L$, Jaén-Olasolo P. Surgical vs. Nonsurgical Treatment of Basal Cell Carcinoma. Actas Dermosifiliogr 2010; 101(8):683-692.

14. Wain RAJ, Tehrani $H$. The plastic \& reconstructive Mohs surgery service. J Plast Reconstr Aesthet Surg 2014; 67(3):331-335.

15. Smeets NW, Krekels GAM, Ostertag JU, et al. Surgical excision vs. Mohs' micrographic surgery for basal cell carcinoma of the face: randomised controlled trial. Lancet 2004; 364(9447):1766-1772.

16. Mosterd K, Krekels GA, Nieman FH, et al. Surgical excision versus Mohs' micrographic surgery for primary and recurrent basal-cell carcinoma of the face: a prospective randomised controlled trial with 5-years' followup. Lancet Oncol 2008; 9(12):1149-1156.

17. Rowe DE, Carroll RJ, Day CL. Mohs surgery is the treatment of choice for recurrent (previously treated) basal cell carcinoma. J Dermatol Surg Oncol 1989; 15(4):424-431.

18. Parlato $C$, Granata $R$, Moraci $A$, et al. Dural Reconstruction in Meningioma Surgery. In: Monleon D. Meningiomas - Management and Surgery. China: InTech, 2012. Chapter 6, Dural reconstruction in meningioma surgery; p. 103124.

19. Rengachary SS, Benzel EC. Calvarial and Dural Reconstruction. U.S.A.: AANS, 1998. Chapter 3, Cranioplasty materials; p. 35-45.

20. Baker SR. Local flaps in facial reconstruction. $3^{\text {rd }}$ Ed. China: Elsevier Saunders; 2014. Chapter 24, Reconstruction of the scalp; p.641667.

21. Janis JE, Leedy JE. Lip, cheek and scalp reconstruction. SRPS 2006; 10(13):1-39.

22. Bayles SW, Hayden RE. Gastro-omental free flap reconstruction of the head and neck. Arch Facial Plast Surg 2008; 10(4):255-259. 
23. Kruse-Losler $B$, Presser $D$, Meyer $U$, et al. Reconstruction of large defects on the scalp and forehead as an interdisciplinary challenge: Experience in the management of 39 cases. Eur J Surg Oncol 2006; 32(9):1006-1014.

24. Thorne $\mathrm{CH}$, Chung KC, Gosain GC, et al. Grabb and Smith's Plastic Surgery. 7th Ed. China: Lippincott Williams \& Walkins, 2014. Chapter 31, Reconstruction of the scalp, calvarium, and forehead; p. 342-351.

25. Wei F, Mardini S. Flaps and Reconstructive Surgery. China: Elsevier Saunders, 2009. Chapter 23, Latissimus dorsi flap; p.287-303.

26. Xua ZF, Suna CF, Duana WY. Clinical anatomical study and evaluation of the use of the free anteromedial thigh perforator flaps in reconstructions of the head and neck. Br J Oral Maxillofac Surg 2013; 51(8):725-730.

27. Bhujel N, Johnston C, Parmar S, et al. An unusual anatomical variant of the vascular anatomy in the anterolateral thigh free flap. Int J Oral Maxillofac Surg 2010; 39(1):94-95.

28. Shawa RJ, Batstone MD, Blackburn TK, et al. The anterolateral thigh flap in head and neck reconstruction: "Pearls and pitfalls". $\mathrm{Br} J \mathrm{Oral}$ Maxillofac Surg 2010; 48(1):5-10.

29. Marsh DJ, Chana JS. Reconstruction of very large defects: a novel application of the double skin paddle anterolateral thigh flap design provides for primary donor-site closure. J Plast Reconstr Aesthet Surg 2010; 63(1):120-125.

30. Agostini T, Lazzeri D, Spinelli G. Anterolateral thigh flap: Systematic literature review of specific donor-site complications and their management. J Craniomaxillofac Surg 2013; 41(1):15-21.

31. Hierner R, vaan Loon J, Goffin J, et al. Free latissimus dorsi flap transfer for subtotal scalp and cranium defect reconstruction: report of 7 cases. Microsurgery 2007; 27(5):425-428.

32. Fattah A, Pollock J, Maheshwar A, et al. Big Bad BCCs: Craniofacial resection and reconstruction for atypical basal cell carcinoma. $J$ Plast Reconstr Aesthet Surg 2010; 63(5):433441.

33. Fattahi T, DiPasquale J. Utility of the pericranial flap in frontal sinus and anterior cranial fossa trauma. Int. J. Oral Maxillofac Surg 2009; 38(12):1263-1267.

34. Uyar Y, Kumral TL, Yıldırım G. Reconstruction of the orbit with a temporalis muscle flap after orbital exenteration. Clin Exp Otorhinolaryngol 2015; 8(1):52-56.

35. Bagheri SC, Bell B, Khan HA. Current Therapy In Oral and Maxillofacial Surgery. China: Elsevier Saunders, 2012. Chapter 64 - The temporalis system of flaps in head and neck reconstruction: temporoparietal fascia and temporalis muscle flaps; p. 527-533.

36. Serra MP, Longhi $P$, Carminati $M$, et al. Microsurgical scalp and skull reconstruction using a combined flap composed of serratus anterior myo-osseous flap and latissimus dorsi myocutaneous flap. J Plast Reconstr Aesthet Surg 2007; 60(10):1158-1161.

37. Arai $H$, Yanai $A$, Nishida $M$, et al. Reconstruction of scalp and cranium defect utilizing latissimus dorsi musculocutaneous and serratus anterior muscle free flaps with interpositional anastomosis of T-shaped flap artery. Skull Base Surg 1995; 5(2):117-121.

38. Abolhoda A, Bui TD, Milliken JC, et al. Pedicled latissimus dorsi muscle flap routine use in highrisk thoracic surgery. Tex Heart Inst $J$ 2009; 36(4):298-302.

39. Chao $\mathrm{AH}, \mathrm{Yu} \mathrm{P}$, Skoracki RJ, et al. Microsurgical reconstruction of composite scalp and calvarial defects in patients with cancer: A 10-year experience. Head Neck 2012; 34(12):1759-1764.

40. Stula D. Cranioplasty: Indications, Techniques, and Results. Wien: Springer-Verleg, 1984. Chapter C, Surgical procedures and techniques of cranial repair; p.57-61.

41. Perisanidis $C$, Herberger $B$, Papadogeorgakis $\mathrm{N}$, et al. Complications after free flap surgery: do we need a standardized classification of surgical complications? Br J Oral Maxillofac Surg 2012; 50(2):113-118.

42. McMahon JD, Maclver $C$, Smith $M$, et al. Postoperative complications after major head and neck surgery with free flap repair prevalence, patterns, and determinants: a prospective cohort study. $\mathrm{Br} J$ Oral Maxillofac Surg 2013; 51(8):689-695.

43. Bianchi B, Copelli C, Ferrari S, et al. Free flaps: outcomes and complications in head and neck reconstructions. J Craniomaxillofac Surg 2009; 37(8): 438-442.

44. Puram SV, Yarlagadda BB, Sethi $R$, et al. Transfusion in head and neck free flap patients: practice patterns and a comparative analysis by flap type. Otolaryngol Head Neck Surg 2015; 152(3):449-457.

45. Kehler U, Hirdes C, Weber C, et al. CSF leaks after cranial surgery-a prospective multicenter analysis. Innov Neurosurg 2012; 1(1):49-53.

46. Quinones-Hinojosa A, Schmidek, S. Operative Neurosurgical Techniques: Indications, Methods and Results. $6^{\text {th }}$ Ed. vol. 2. China: Elsevier Saunders, 2012. Chapter 138, Management of cerebrospinal fluid leaks; p.1579-1595.

47. Korinek AM, Baugnon T, Golmard JL, et al. Risk factors for adult nosocomial meningitis 
after craniotomy: role of antibiotic prophylaxis. Neurosurg 2006; 59(1):126-133.

48. Pichierri $A$, Ruggeri $A$, Donnarumma $P$, et al. Postoperative Extradural Hematomas. J Neurol Surg 2013; 74(1):25-28.

49. Sherry KR, Reid LA, Wilmshurst AD. A five year review of basal cell carcinoma excisions, $J$ Plast Reconstr Aesthet Surg 2010; 63(9):14851489.

50. Liu FF, Maki E, Warde $P$, et al. A management approach to incompletely excised basal cell carcinomas of skin. Int J Radiat Oncol Biol Phys 1991; 20(3):423-428.
51. Ríos-Buceta L. Management of basal cell carcinomas with positive margins. Actas Dermosifiliogr 2007; 98(10):679-687.

52. Birgfeld C, Neligan P. Surgical Approaches to Facial Nerve Deficits. Skull Base 2011; 21(3):177-184.

53. Penel N, Yann Mallet $Y$, Roussel-Delvallez $M$, et al. Factors determining length of the postoperative hospital stay after major head and neck cancer surgery. Oral Oncol 2008; 44(6):555-562.

54. Miller MJ, Swartz WM, Miller RH, et al. Cost analysis of microsurgical reconstruction in the head and neck. J Surg Oncol 1991; 46(4):215277. 